\title{
STUDY OF SAMPLES STRENGTH OF MATERIAL FORMED BY THE PROCESSES OF COMPACTION, EXTRUSION AND TUMBLING GRANULATION
}

\author{
Peter Peciar*, Radovan Ružinský, Adam Guštafík, Mária Karlová, \\ Matúš Čierny, Roman Fekete, Marián Peciar
}

\author{
Slovak University of Technology in Bratislava, Faculty of Mechanical Engineering, Institute of Process \\ Engineering, Námestie Slobody 17, 81231 Bratislava, Slovakia \\ * corresponding author: peter.peciar@stuba.sk
}

\begin{abstract}
In a period of industrial expansion, protection of the environment is often neglected during the mass manufacture of products. One of the problems of our society that is necessary to face at present is the provision, processing and then usage of waste composed of fine particles that are extremely dangerous for mankind. This study looks at the processing of the fine dust resulting from the manufacture of brake pads. The selected technologies for the process of dust treatment were compaction, extrusion and tumbling granulation, and their consequent comparison with the strength of a break and disintegration of agglomerates from fine dust. The experiments were performed on a unique equipment that made it possible to process such dust in the form of larger units and thus reduce their dustiness, with this dust being reintroduced into the technologies for repeat processing or used for energy processing, in a cement kiln, for example.
\end{abstract}

KEYWORDs: Particulate material, waste powder, wasteless technologies, process, agglomeration.

\section{INTRODUCTION}

With the advent of new, modern and highly automated technologies in various industries, emphasis is increasingly being placed on their impact on the environment throughout their lifecycle. One of the key goals, therefore, is to ensure that potential waste is analysed in the design of new plants and, if possible, to use new, modern, wasteless technologies in its processing or disposal. With the development of new production technologies and methods, material dimensions are shifting increasingly to smaller values; from this, there follows the need to look at this material, and thus the waste generated, as a classical particle system with all its regularities and complications. Such a particulate system impacts a wide range of industries, including chemical or pharmaceutical as well as the rapidly evolving construction and automotive industries. The area of agglomeration belongs among the basic processing operations of particle systems. Modern technologies of processing particulate material by agglomeration can be divided into two basic groups. The first group is wet technologies, where agglomeration fluid acts to strengthen the binding forces between the particles. This group includes extrusion, tumbling granulation, high-shear granulation and fluid granulation processes. These processes, along with their many advantages, also have adverse aspects, the most prevalent of which is the necessity to dry the material and the resulting energy demand for removing the excess liquid from the material or waste. The second group, which dominates currently, is the technology that can be called dry technology.
This group includes tableting processes as well as continuous compaction and briquetting processes. The paper deals with the example of precise processing of fine grain waste from the final grinding operation of a precision product in the automotive segment, which is usually deposited in a landfill but which, after the agglomeration transformation, can be further used as a secondary raw material in the production cycle.

The chosen application of a non-waste technology in the automotive sector is the processing of fine grained dust from the final grinding operation of brake lining segments. In common practice, this waste is deposited in a landfill where it poses a potential environmental risk and it is necessary, due to its size and chemical composition, to treat it as hazardous waste. The goal to processing this very fine dust is the correct design of an agglomeration technology, which can effectively return this dust to the production process or to recycling, whether material or energy. For such a very fine dust, it is possible to use a variety of agglomeration technologies, either without the addition of a binder or with only a very small amount of agglomerating liquid. The most suitable dust-handling technology is dry compaction without the addition of any binder. An agglomeration technology where only minimal liquid is used is the tumbling granulation. The other categories of agglomeration technologies involve an extrusion process where the feedstock is a paste, in this case, dust with water, agglomerating liquid - binder and wetting agent. 


\subsection{COMPACtion PROCESS}

The theory describing the process of compaction, and therefore the correct design of the compactor, has been investigated by several authors. One of the most wellknown is J. R. Johanson 1 6. In his work, he deals predominantly with the flow of material in the compactor, which results in a mathematical model which puts into relation the material properties, the operating conditions of the compacting process and the dimensions of the compactor. Johanson's mathematical model answers the question of what the compactor dimensions and the forces between the rolls should be in order to achieve the necessary pressure for the material at a given temperature. It is assumed that the compacted material is compressible, isotropic, and managed according to the effluent function proposed by Jenike and Shield [7, 8].

It was Johansson who described the compaction of a particulate material through a two-roll compactor by the so-called nip angle $\alpha_{N}$. This angle separates the slip area and the area of compression. In the slip area, in the zone over the nip angle, a mutual movement occurs between the surface and the material. The material is acted on by its own weight or by the force effect of the screw, forced feeding, and to a small extent by the shear stress from the rolls through which the material is dragged into the area between the rolls. In this zone, the particles of the material change position, and displacement of a substantial part of the air contained in the material occurs. In the area of the pressing zone under the nip angle, the material on the surface of the rolls moves at the same speed as the surface speed of the rolls. The effects of wall friction are gradually reduced, and, on the contrary, the normal components of the stress from the rolls begin to work. In this area, the particles of the material deform and the material becomes compact 8.

The pressure ratios for the zone above the nip angle can be calculated by using bulk material mechanics. The result is the relationship (1) for the distribution of the pressure gradient above the nip angle.

$$
\frac{\mathrm{d} \sigma_{\theta}}{\mathrm{d} \theta}=\frac{-4 \sigma_{\theta}\left(\frac{\pi}{2}-\theta-\lambda\right) \tan \delta \cos \theta}{\left(1+\frac{s}{D}-\cos \theta\right)\left[\cot \left(\frac{\frac{\pi}{2}+\theta+\lambda}{2}-\nu\right)-\cot \left(\frac{\frac{\pi}{2}+\theta+\lambda}{2}+\left(\frac{\pi}{4}-\frac{\gamma}{2}\right)\right)\right]}
$$

The procedure for derivation and solution of equation (1] is given in works [8-10]. Johanson used singleaxis compressibility to describe the strain gradient distribution under the nip angle. The relation to the stress distribution at the nip angle has the form of equation (2).

$$
\frac{\mathrm{d} \sigma_{\theta}}{\mathrm{d} \theta}=\frac{-K \sigma_{\theta}\left(2 \cos \theta-1-\frac{s}{D}\right) \sin \theta}{\frac{s}{D}+\left(1+\frac{s}{D}-\cos \theta\right) \cos \theta}
$$

Based on the relationship (2), it is possible to modify the relation (3) to compute the diameter of the rolls of the compactor. The exact derivation of the relationship (3) is given in [8].

$$
D=\frac{(d+s)\left(\frac{p_{m}}{R_{1} p_{0}} \frac{1-\sin \delta}{1+\sin \delta}\right)^{\frac{1}{K}}-d-s \cos \alpha_{N}}{\left(1-\cos \alpha_{N}\right) \cos \alpha_{N}}
$$

\subsection{Extrusion PROCESS}

The basic difference between the extrusion process and the above mentioned technologies is the amount of liquid in the processed material. In order to secure the flow of material in the extruder and its extrusion into the matrix, it is necessary to get the material into paste form.

A paste is a two- or three- phase system, the important properties of which are the following:

- compressibility of the skeleton created by grains of a particulate material described by some models of compressibility,

- surface tension and wetting of the particle surfaces, which is the autonomous scope,

- pore skeleton resistance that inhibits the liquid motion in the direction of the pressure gradient.

Solving the problems of the isothermal flow with various densities and viscosities requires a knowledge of the relation between speed, pressure, density and viscosity distribution for the specific system.

The extrusion process can theoretically be described on the basis of the theoretical knowledge of Continuity Relation along with Motion Equation and State Equation [11,13].

\subsubsection{Continuity Relation}

The paste is a dissipation system which can be compressed under pressure, but its expansion is not reversible. The motion of a paste within the extruder is described by the continuity relation for the compressible liquid (4).

$$
\frac{\partial \rho}{\partial t}+\frac{1}{r} \frac{\partial}{\partial r}\left(\rho r v_{r}\right)+\frac{1}{r} \frac{\partial}{\partial \theta}\left(\rho v_{\theta}\right) \frac{\partial}{\partial z}\left(\rho v_{z}\right)=0
$$

It is not easy to determine the velocity or the density of the components. Thus the equation becomes unsolvable due to its complexity [1].

\subsubsection{Motion Equation}

One side effect of the process is the movement of the liquid within the pores of the grainy skeleton of a powder material during its extrusion in the paste form [13]. The compression of the powder under the extrusion pressure is the primary factor causing this motion. The degree of compression depends on the ratio between the normal and shear stress. If normal stress dominates over the compression of the skeleton, the voidage decreases and the liquid phase migration 
in the direction of the pressure gradient occurs. But if shear stress increases, the apparent viscosity goes down and the extrusion pressure also decreases. This is provided by the following relation (5).

$$
\overline{\bar{\sigma}}=P \overline{\bar{\delta}}+\overline{\bar{\tau}}
$$

The extrusion pressure $\mathrm{P}$ can be measured by a pressure sensor. The normal stress tensor $\overline{\bar{\sigma}}$, is responsible for the compression of the skeleton. The tensor for the shear stress $\overline{\bar{\tau}}$ is the element whose value depends on the rheological properties of the paste and the shear rate. Upon analysing the previous relations (4) and (5), it can be inferred that if the motion of a liquid in the voids is minimal, skeleton compression must be restricted. This means that the normal stress is minimal and the shear stress, together with the shear rate, should be the prime factors affecting the skeleton compression and thus liquid motion [11.

\subsubsection{State Equation}

In the case of a paste, it is necessary to separate the three factors which are in the interaction. The base is a solid phase created by grains of the material in contact with each other. Among them are the voids which are filled by either a liquid or a gas. The gas volume is generally insignificant and can be neglected. For ordinary extrusion pressures, the liquid is uncompressible. Considering these conditions, the state equation has the general form 6 .

$$
\rho=f(P)
$$

As the skeleton of the paste consists of grains among which are voids, so the gas and liquid can freely flow inside these voids according to their compression under the extrusion pressure. It can be assumed that the main influence on the paste's density is the skeleton's compressibility. To test this parameter, the theory of a single-axis compressibility can be applied [11.

\subsection{Tumbling GRANULATION PROCESS}

The process of tumbling granulation is based on the formation of agglomerates by rolling and tumbling the powder after the rotating tilting of the granulating disc. The fine granules are discharged to the surface, with the coarser granules at the bottom. The resulting final product is discharged at the lower edge of the granulating disc.

On the granulating disc, there are particles moving during the granulation under the influence of gravitational and centrifugal forces. The key operating parameter for the rotating disc is the critical speed at the rotational speed of the disc $N_{c}$, which is defined according to the relationship (7).

$$
N_{c}=\sqrt{\frac{g \sin \beta}{2 \pi^{2} D}}
$$

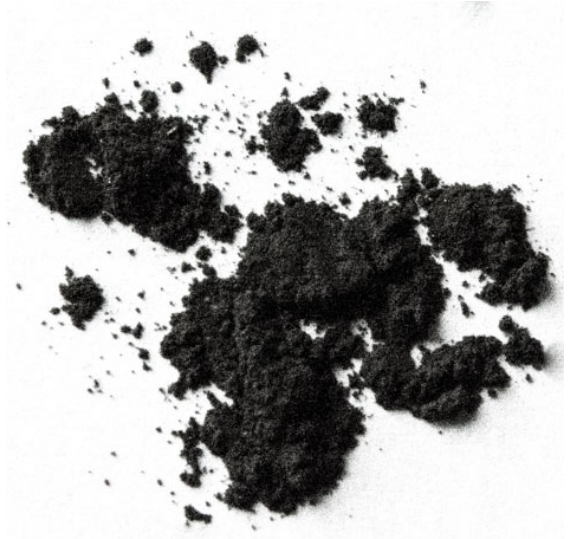

Figure 1. Powder from brake lining production.

Tumbling granulators are typically operated in the range of $50 \%$ to $75 \%$ of the critical velocity $N_{c}$ with an angle $\beta$ between $45^{\circ}$ and $55^{\circ}$. If the speed is too low, instead of turning, the weight of the particles is shifted to the disc. If the speed is too high, the particles attach to the edge or may be expelled from the disc. The optimum drum speed is also influenced by the flow properties of the material. During the tumbling granulation process, the following partial processes are carried out: nucleation, consolidation, granule growth by coalescence and coating 14 .

\section{EXPERIMENTAL MATERIAL}

The experimental material was the waste dust from the production of brake linings (Fig. 1, Fig. 2). In the processing of powder materials, it is necessary to know the distribution characteristics of the experimental material. Distribution characteristics for the experimental material were made by Malvern Morphologi G3 and Malvern Mastersizer 3000 and shown in Figure 3. The results of both analyses are in a perfect agreement (Malvern Mastersizer 3000 - DV $(10)=6.65 \mu \mathrm{m}$, $\operatorname{DV}(50)=27.8 \mu \mathrm{m}, \mathrm{DV}(90)=151 \mu \mathrm{m})$. The properties of the experimental material are given in [15], and were identified by standard procedures [16 20].

\section{EXPERIMENTAL EQUIPMENT AND EXPERIMENTAL MEASUREMENTS}

\subsection{COMPACTION PROCESS}

For the modification of the waste dust by compaction into stable agglomerates, a laboratory compactor was designed and made at the Institute of Process Engineering of the Faculty of Mechanical Engineering of STU in Bratislava. The design solution of the laboratory compactor is in Figure 4 . In the laboratory compactor, it is possible to select the type of rolls (smooth rolls, finely grooved, profiled, briquetting rolls) and regulate the rotation speed of the rolls and the frequency of rotation of the filling screw. During the compacting process, it is possible to record the spar force between the rolls, the torque of the 


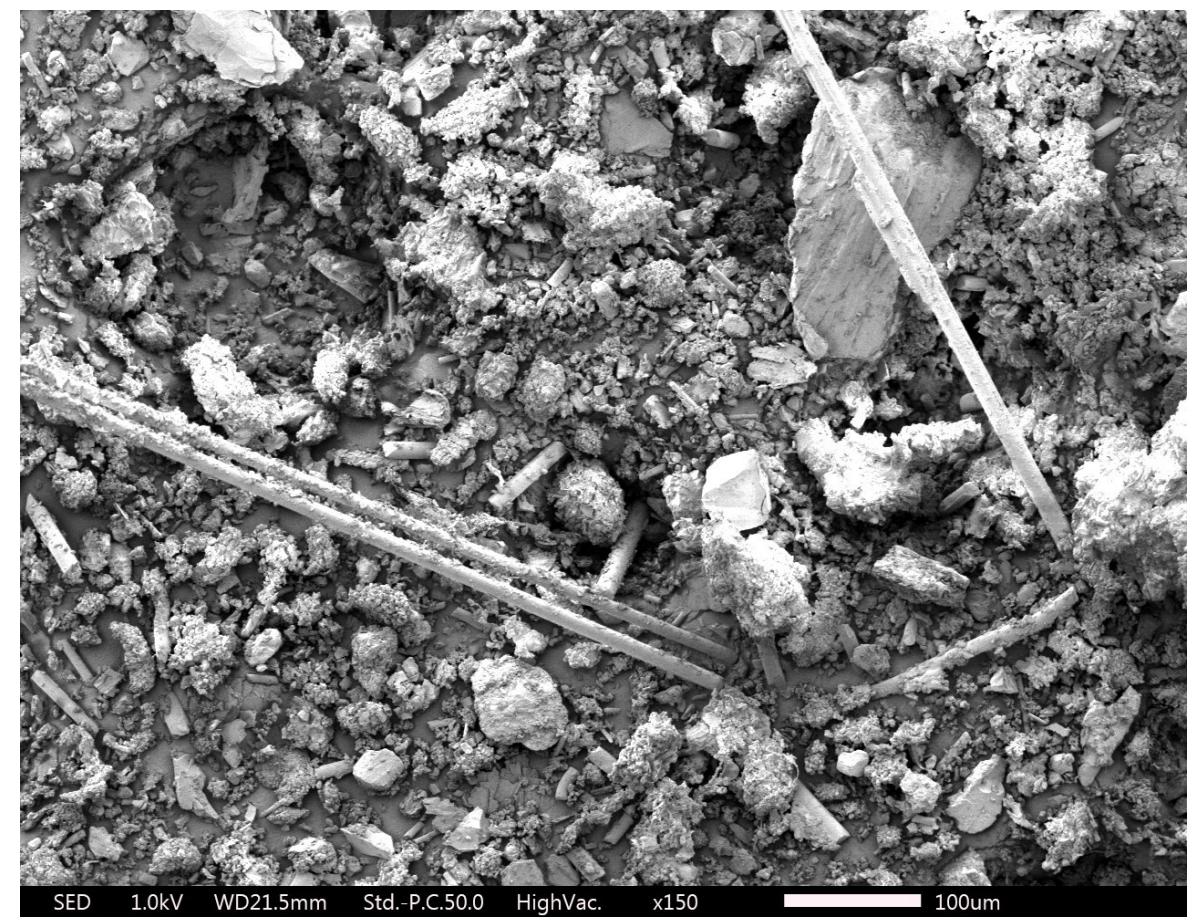

Figure 2. Picture of powder at 150-times enlargement, made by a JoelR Scanning electron microscope. (SED-1.0kVWD21.5mm-Std.P.C.50.0-HighVac-x150) [15]

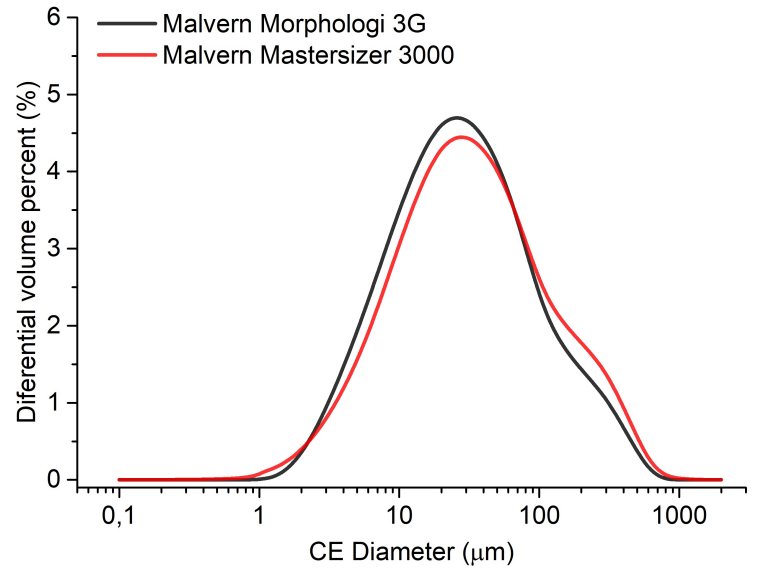

FigURE 3. Distribution characteristic of pure raw material created by Malvern Morphologi G3 and Malvern Mastersizer 3000 equipment. [15]

compactor rolls, and the torque of the filling screw. On the basis of the measured data from experiments using equations (2) and (3), it is possible to design the optimal working conditions for the compactor process as well as the smallest suitable diameter of the rolls of the compactor.

From the waste dust compacting experiments, the best design appeared to be slightly profiled rolls, with the product of the compactor being a continuous finegrained strip (Fig. 5), which was disintegrated into stable agglomerates (Fig. 6).

Experiments using the compaction process were performed at two different rotations of the compactor rolls, which represented individual product mass flows $(1.35 \mathrm{rpm}-22 \mathrm{~kg} / \mathrm{h}, 6.75 \mathrm{rpm}-110 \mathrm{~kg} / \mathrm{h})$.

\subsection{EXTRUSION PROCESS}

Extrusion experiments using an agglomerating binder in the form of an aqueous solution of water glass and wetting agents were performed on a patented axial rotary head extruder (Fig. 7) designed at the Institute of Process Engineering of the Faculty of Mechanical Engineering STU in Bratislava. The device is a unique, self-rotating conical head that has a beneficial effect on fluid migration in the extruder head. On the basis of the experiments performed, the optimal parameters of the extrusion process were found. Stable agglomerates in the form of hollow cylinders (Fig. 8) were produced [12].

Experiments using the extrusion process were carried out under various combinations of paste compositions - waste dust, water, binder and wetting agent (45\% liquid in the sample, liquid - $70 \%$ water, $24 \%$ water glass, $6 \%$ wetting agent). On the basis of these experiments, it was found that the rotation frequency of the worm had an influence only on the weight, while the effect of the rotation speed of the extruder head also proved favourable for the strength properties of the extrudates produced, while simultaneously maintaining the paste composition [11, 12].

\subsection{TUmbling GRANULATION PROCESS}

The experiments employed a laboratory granulator with a diameter of $395 \mathrm{~mm}$ granulating disc scanned at an angle of $50^{\circ}$ with respect to the horizontal. The 

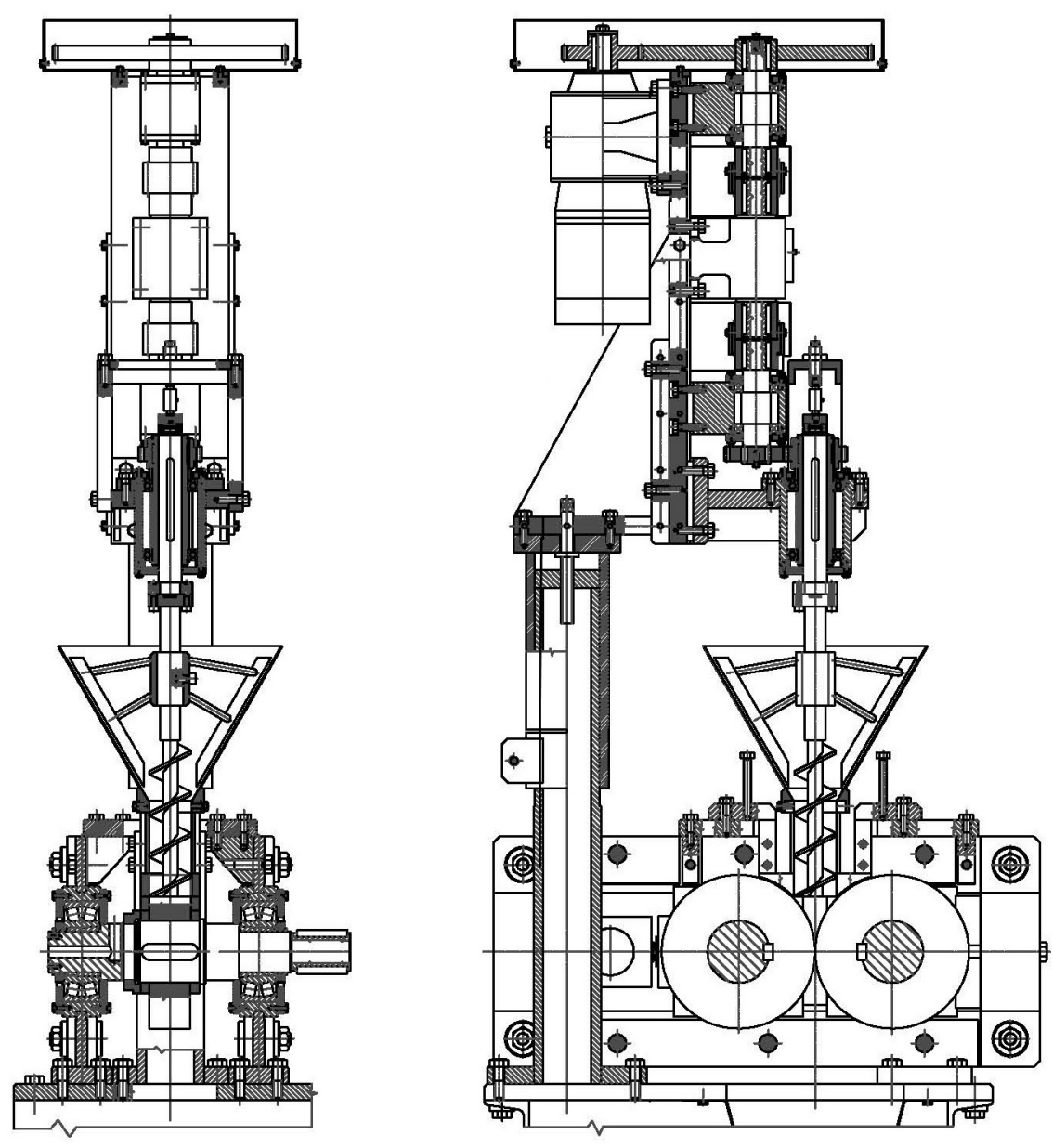

Figure 4. Design solution of laboratory compactor. 21]

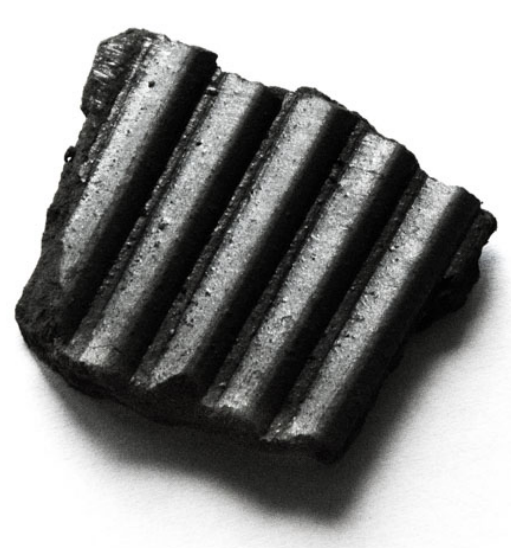

FiguRE 5. Profiled strip of experimental material from compaction process.

formed agglomerate is depicted in Figure 9 Experiments using the tumbling granulation process were performed at various adjustments to the speed of rotation of the granulating disc (10 rpm, $15 \mathrm{rpm}, 20 \mathrm{rpm})$. The liquid injected through the nozzle contained water with the addition of a wetting agent and a low concentration of a binder in the form of liquid glass

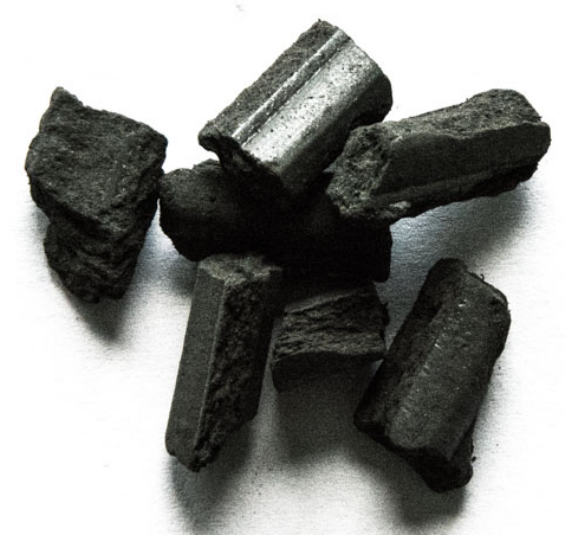

FiguRE 6. Final product produced by compaction process.

(liquid - $70 \%$ water, $24 \%$ water glass, $6 \%$ wetting agent).

\section{Results}

The samples formed in the processes of compaction, extrusion and tumbling granulation were examined in detail for breaking and disintegration. The neces- 


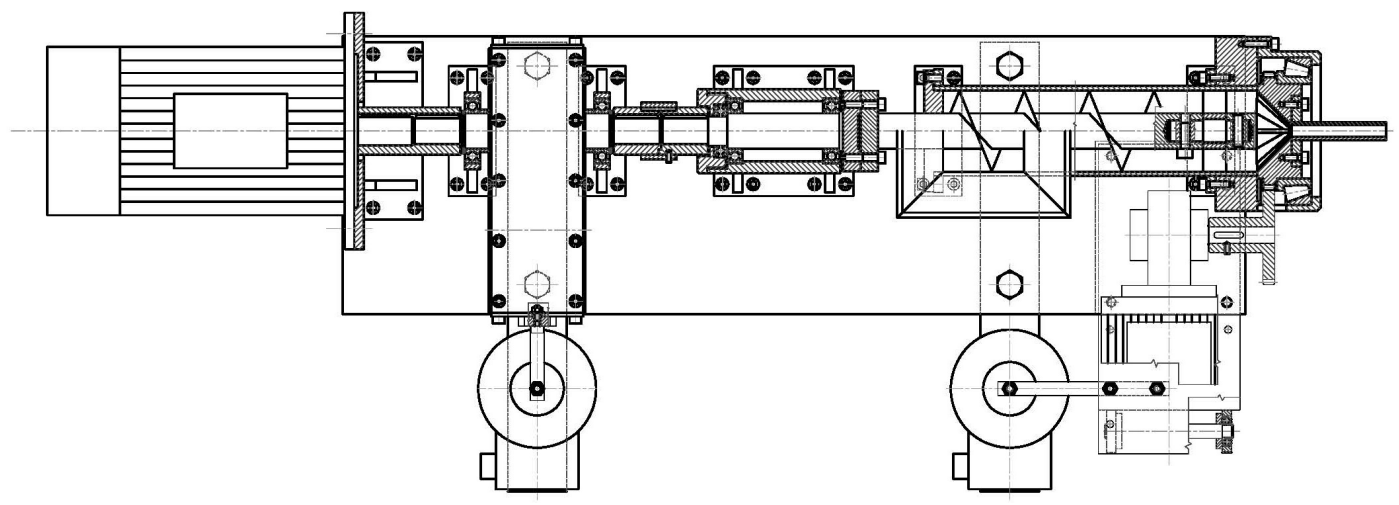

FiguRE 7. Design solution of laboratory axial extruder with rotatable die head. 22]

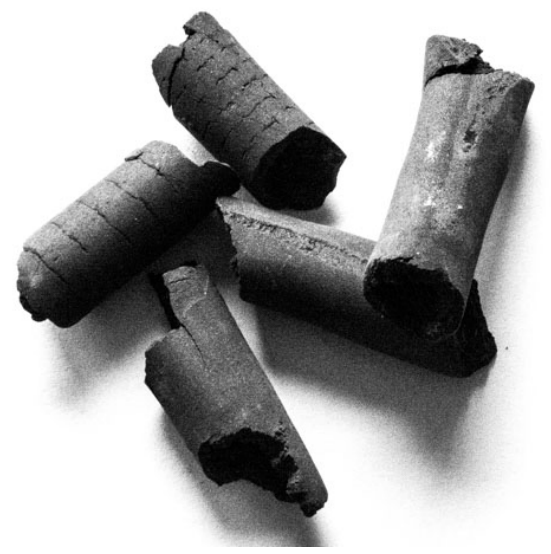

FIgURE 8 . Final product produced by extrusion process.

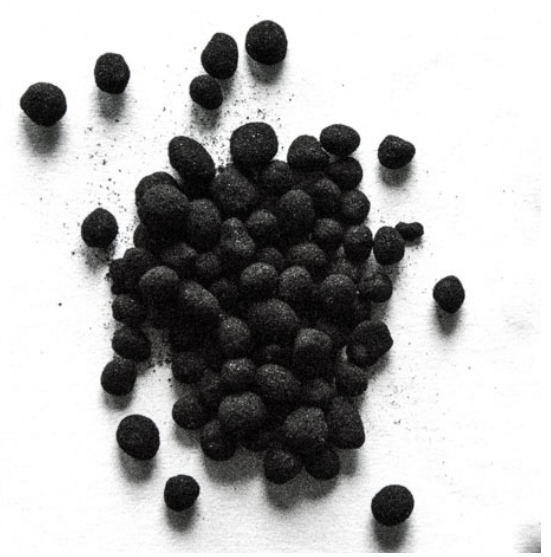

Figure 9. Final product produced by tumbling granulation process.

sary force for breaking and disintegration of the test samples was determined by evaluating of the measurements. The physical principle for identifying the force needed to break the sample in the compaction and extrusion process is shown in Figure 10 a), the force needed to disintegrate the sample in the compaction and extrusion process is shown in Figure 10 b) and the force needed to disintegrate the sample in the granulation process is shown in Figure 10 c). The
Force needed to break the sample

a)

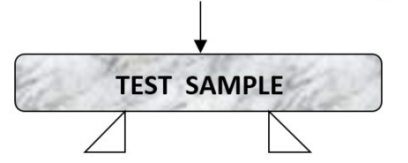

Force needed to disintegrate the sample

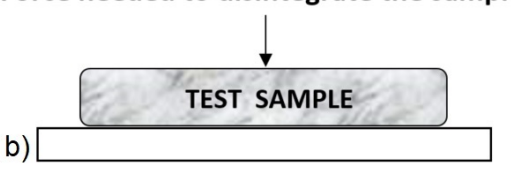

Force needed to disintegrate the sample

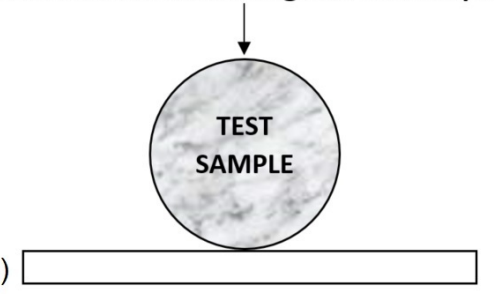

Figure 10. Physical principle of testing sample against breaking and disintegration: a) breaking in compaction and extrusion processes; b) disintegration in compaction and extrusion proces; c) disintegration in granulation process.

results of the forces needed to break and disintegrate the sample in the compaction, extrusion and the granulation processes are shown in Figure 11 and Figure 12 respectively.

In a comparison of the tests for breaking, the technologies of compacting and extrusion processes were almost equal, with only minimal differences. At lower compactor rotations $(1.35 \mathrm{rpm})$ the strength was greater than at higher speeds $(6.75 \mathrm{rpm})$, while the force of forced feeding had no significant influence. This phenomenon was caused by the better draw of air between the particles, and with low rotations, better compaction of the material took place. In the extrusion process with increased revolutions of the screw extruder, breaking strength increased, but the frequency of rotation of the main extruder had lit- 


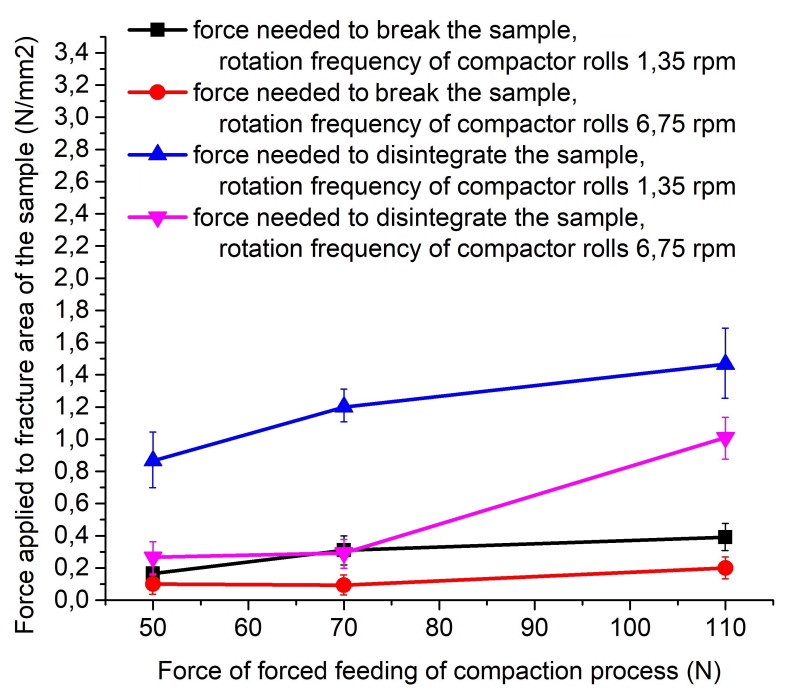

Figure 11. The results of the forces needed to break and disintegrate in the compaction process. 15]

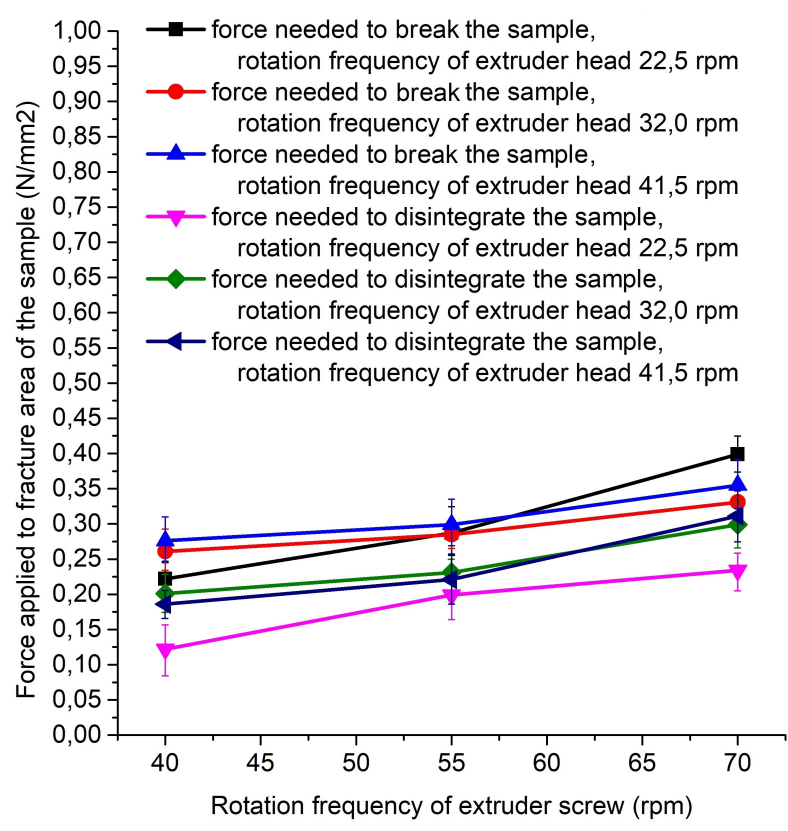

Figure 12. The results of the forces needed to break and disintegrate in the extrusion process.

tle effect. As can be clearly seen from the recorded values, with the increasing rotation frequency of the main extruder, the strength of the samples decreased at first, and then started to increase. This could be caused by the migration of the liquid in the head of the extruder, even though these measured data can be evaluated as relatively equal.

\section{Conclusion}

In a comparison of the tests for disintegration, agglomerates from the compaction process came in as the strongest, while at slower rotations of the compactor rolls $(1.35 \mathrm{rpm})$, the achieved values were in the range of 0.7 to $1.7 \mathrm{~N} / \mathrm{mm}^{2}$ in dependence on the strength

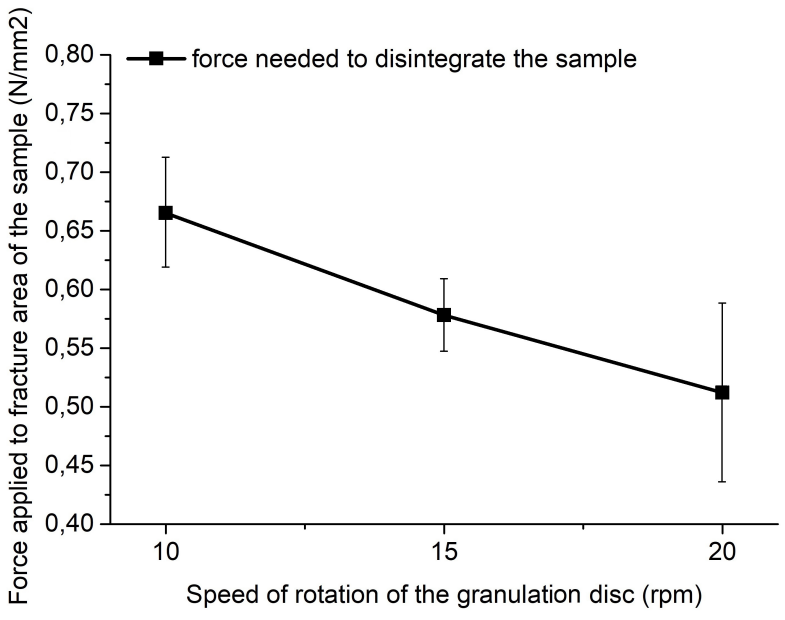

FiguRE 13. The results of the forces needed to break and disintegrate in the granulation process.

of the forced feeding. All the other measured data, just like in the extrusion and packaged granulation processes, were significantly lower.

Experimental measurements have shown that technologies that convert very fine dust into agglomerates of a stable form can be included in initial production cycles, where large amounts of waste dust are accumulated.

Due to the need for the binder addition and wetting, modification of waste dust by extrusion and tumbling granulation technologies is not primarily intended for direct material recycling. This type of treatment of waste dust in the form of stable agglomerates is suitable mostly for energy recycling, where it is possible to transport the treated dust and feed it into cement kilns as an energy source. This is very problematic in the case of fine dust waste. With the introduction of the process of extrusion or of tumbling granulation, however, further complications arise with the removal of the added liquid and the necessity of drying the agglomerate produced, which has a negative impact on the energy balance of the entire production line.

\section{LIST OF SYMBOLS}

$\alpha_{N}$ Nip angle $\left[^{\circ}\right]$

$\beta$ Disc angle $\left[{ }^{\circ}\right]$

$\delta \quad$ Effective angle of internal friction $\left[^{\circ}\right]$

$\overline{\bar{\delta}} \quad$ Unit tensor $[1]$

$\lambda$ Angle between direction of $\sigma_{1}$ and tangent to roll surface $\left[^{\circ}\right]$

$\rho$ Density $\left[\mathrm{kg} \mathrm{m}^{-3}\right]$

$\sigma_{\theta}$ Stress between the rolls at angle $\theta[\mathrm{Pa}]$

$\sigma_{1}$ Major principal stress $[\mathrm{Pa}]$

$\overline{\bar{\sigma}} \quad$ Normal stress tensor $[\mathrm{Pa}]$

$\overline{\bar{\tau}} \quad$ Shear stress tensor $[\mathrm{Pa}]$

$\theta \quad$ Angular position in roll bite $\left[^{\circ}\right]$

$\theta$ Angle of rotation $\left[^{\circ}\right]$

$\nu \quad$ Angle $\frac{\pi}{4}-\frac{\delta}{2}\left[{ }^{\circ}\right]$ 
$d$ Depth of grooves on the compactor rolls [m]

$g$ Gravitational acceleration $\left[\mathrm{m} \mathrm{s}^{-2}\right]$

$p_{m}$ Maximum compression pressure $[\mathrm{Pa}]$

$p_{\mathrm{o}}$ Inlet compression pressure $[\mathrm{Pa}]$

$r$ Radius [m]

$s \quad$ Gap between the rolls [m]

$t$ Time [s]

$v$ Speed $\left[\mathrm{m} \mathrm{s}^{-1}\right]$

$z$ Axis $[\mathrm{m}]$

$D$ Diameter of the compactor rolls [m]

$D$ Disc diameter $[\mathrm{m}]$

$K$ Johanson's compressibility factor [1]

$N_{c}$ Critical rotational speed $\left[\mathrm{s}^{-1}\right]$

$P \quad$ Extrusion pressure $[\mathrm{Pa}]$

$R_{1} \quad$ Ratio of stress [1]

\section{ACKNOWLEDGEMENTS}

This article was created with the support of the Ministry of Education, Science, Research and Sport of the Slovak Republic within the Research and Development Operational Programme for the project "University Science Park of STU Bratislava", ITMS 26240220084, co-funded by the European Regional Development Fund.

This work was supported by the project "Development of Research Infrastructure STU", project no. 003STU-2$3 / 2016$ by the Ministry of Education, Science, Research and Sport of the Slovak Republic.

The authors wish to acknowledge the Ministry of Education, Science, Research and Sport of the Slovak Republic for the financial support of this research by grant KEGA 016STU-4/2019 and Slovak Research and Development Agency by grant APVV-18-0348.

The authors would like to thank Mr. Kevin Slavin for the language correction.

\section{REFERENCES}

[1] J. R. Johanson. A rolling theory for granular solids. Journal of Applied Mechanics pp. 842-848, 1965.

[2] J. R. Johanson. Factors influencing the design of roll-type briquetting presses. Proceeding of 9-th Biennal Briquetting Conference 9:17-31, 1965. Denver, USA.

[3] J. R. Johanson. Feeding roll presses for stable roll operation. Proceeding of 18-th Biennial Conference of The Institute for Briquetting and Agglomeration 18:209-227, 1983. Colorado Springs, USA.

[4] J. R. Johanson. Fluid entrainment efects in roll press compaction. Powder Handling and Processing 2:183-185, 1989.

[5] J. R. Johanson. Reducing compacting roll wear through ecient roll face design and operating conditions. Proceeding of 16-th Biennial Conference of the Institute for Briquetting and Agglomeration 16:153-161, 1979. San Diego, Colorado, USA.

[6] J. R. Johanson. Reducing air entrainment problems in your roll press. Powder and Bulk Engineering 43, 1989.

[7] A. W. Jenike, R. T. Shield. On the plastic flow of coulomb solids beyond original failure. Journal of Applied Mechanics 26:599-602, 1959.
[8] P. Peciar, O. Macho, E. Eckert, et al. Design of particulate material compactor rolls diameter. Acta Polytechnica 57 (4):263-271, 2017. ISSN 1805-2363, DOI:10.14311/AP.2017.57.0263

[9] M. Hubert. Application of compresibility equations in the theory of compactor design. Dissertations thesis. STU, Faculty of Mechanical Engineering, Bratislava, 2000. (In Slovak).

[10] M. Balicki. Numerical methods for predicting roll press powder compaction parameters. Centre Poudres Et Procédés, 2003.

[11] M. Peciar, R. Fekete, P. Peciar. Agglomeration technologies of processing powder wastes. Solid State Phenomena 244:121-129, 2016. ISSN 1012-0394, DOI:10.4028/www.scientific.net/SSP.244.121

[12] P. Peciar, R. Fekete, M. Peciar, O. Macho. Extrusion processing of powder from manufacture of brake linings. Proceeding of 42nd International Conference of Slovak Society of Chemical Engineering 42:793-801, 2015.

[13] J. Bendow, J. Bridgwater. Paste flow and Extrusion. ClarendonPress, Oxford, 1993.

[14] J. Litster, B. Ennis. The Science and engineering of granulation processes. Springer, 2004. ISBN 978-90-481-6533-9.

[15] P. Peciar, O. Macho, E. Eckert, et al. Modification of powder material by compaction processing. Acta Polytechnica 57 (2):116-124, 2017. ISSN 1805-2363, DOI:10.14311/AP.2017.57.0116

[16] L. Grossmann, J. Tomas, B. Csoke. Compressibility and flow properties of a cohesive limestone powder in a medium pressure range. Granullar Matter 6:103-109, 2004. DOI:10.1007/s10035-004-0164-Z

[17] G. Lumay, F. Boschini, K. Traina, et al. Measuring the flowing properties of powders and grains. Powder Technology 224:16-27, 2012. DOI:10.1016/j.powtec.2012.02.015

[18] D. Geldart, E. Abdullah, A. Verlinden. Characterisation of dry powders. Powder Technology 190:70-74, 2009. DOI:10.1016/j.powtec.2008.04.089

[19] U. Ulusoy, I. Kursun. Comparison of different 2d image analysis measurement techniques for the shape of talc particles produced by different media milling. Minerals Engineering 24:91-97, 2011. DOI:10.1016/j.mineng.2010.05.011.

[20] C. Levoguer. Using laser diffraction to measure particle size and distribution. Metal Powder Report 68:15-18, 2013. DOI:10.1016/S0026-0657(13)70090-0

[21] P. Peciar. Research of the selected processes of particulate materials processing. Habilitation thesis. STU, Faculty of Mechanical Engineering, Bratislava, 2018. ISBN 978-80-227-4801-8 (In Slovak).

[22] R. Fekete, M. Peciar, P. Peciar. Axial extruder with rotatable die head. Patent no. SK 288515. Registration of patent no. 5014-2014. WIPO no. EP 3131732 A1, WO2015159198A1, PCT no.: EP20150724765, PCT/IB2015/052668. Industrial Property Office of the Slovak Republic, Banská Bystrica, Slovakia, 2018. 